\title{
"Desmanche": notas sobre as disputas em torno da legitimidade das políticas LGBT no Brasil
}

\author{
- Vinícius Pedro Correia Zanoli \\ Universidade Estadual de Campinas, Campinas, Sáo Paulo, Brasil \\ - Thiago Henrique de Oliveira Falcáo \\ Universidade Estadual de Campinas, Campinas, Sáo Paulo, Brasil
}

DOI 10.11606/issn.2316-9133.v24i24p264-289

\begin{abstract}
resumo Este artigo baseia-se em pesquisas sobre políticas municipais LGBT em Campinas. A metodologia empregada congrega observação participante, análise documental e entrevistas com gestores e ativistas municipais. Aqui, apresentamos a criação da primeira política pública brasileira a oferecer assistência social, jurídica e psicológica para LGBT, o Centro de Referência LGBT de Campinas. Em um olhar sobre essa e outras políticas municipais, iluminadas pelo contexto nacional mais amplo, buscamos entender de que forma um serviço com menor legitimidade política e social atua em um contexto de disputa do lugar social da homossexualidade entre diversos atores sociais. Argumentamos, assim, que o caso campineiro é elucidativo do que ocorre com as políticas LGBT no Brasil. Ainda que exista um processo de implementação de algumas políticas, elas trouxeram poucos resultados concretos, ao que se soma a resistência em forma de projetos de lei que visam barrar o processo de constituição dos LGBT enquanto sujeitos de direito.
\end{abstract}

palavras-chave Movimento LGBT; Movimentos sociais; Homossexualidade; Política; Políticas públicas.

\section{Notes on the disputes around LGBT policies legitimacy in Brazil}

abstract This article is based on researches on LGBT policies in Campinas. The methodology uses participant observation, documental analysis and interviews with officials and activists. Here, we present the creation of the first Brazilian public policy to offer social, legal and juridical assistance to LGBT, the LGBT Center of Campinas. By taking into account this and other public policies, enlightened by a broader national context, we seek to understand how a public service with less social and political legitimacy works in a context of intense dispute around the social place of homosexuality. We argument thus that 
the Campinas' situation is representative of what happens with LGBT policies in Brazil. Although there is a process of implementation of some policies, they brought only few concrete results, alongside with the resistance in form of legislative acts aiming to stop the process of constitution of the LGBT as subjects of rights.

keywords LGBT movement (Brazil);, Social movements (Brazil); Homosexuality; Politics; Public policies

O que se convencionou chamar na atualidade de movimento de Lésbicas, Gays, Bissexuais, Travestis e Transexuais (LGBT) no Brasil tem seu surgimento datado em fins da década de 1970, na cidade de Sáo Paulo (MACRAE, 1990). No decorrer de sua trajetória, as questóes mobilizadas por esse movimento atingiram grande visibilidade política (FACCHINI, 2012; MARIANO, 2010). Mostra disso está na centralidade que essa temática adquiriu no debate eleitoral nacional, no ano de 2010, sobretudo no segundo turno, em que os candidatos precisaram se posicionar acerca do reconhecimento, ou não, de LGBT como sujeitos de direitos para a obtenção de apoio eleitoral, fazendo com que muitos políticos evitassem a discussão, ou acabassem por se posicionar contra projetos considerados como caros ao movimento, como a criminalização da homofobia e a legalização do casamento civil entre pessoas do mesmo sexo.

Além da visibilidade, entre seu surgimento e os dias atuais, o movimento passou por forte processo de institucionalizaçáo, marcado por parcerias firmadas entre organizaçóes ativistas e o Estado, principalmente no enfrentamento à epidemia de HIV/Aids (PARKER, 2009; DANILIAUKAS, 2011). Esse processo resultou na implementação de algumas políticas voltadas para o combate à homofobia no Brasil, como o programa Brasil sem Homofobia (BSH), em âmbito federal, além de diversas políticas locais. Dentre tais políticas, destacamos a criação do Centro de Referência LGBT de Campinas (CR), primeira política pública brasileira de combate à homofobia a oferecer assistência social, jurídica e psicológica para LGBT, implementado antes mesmo da criação do programa Brasil sem Homofobia. Sua criação é fruto das relações estabelecidas entre a Prefeitura Municipal e o movimento LGBT da cidade através do Orçamento Participativo de Campinas (OP).

Neste artigo, procuramos problematizar a produção em curso dos LGBT enquanto sujeitos de direito no Brasil, a partir das relaçóes entre processos políticos locais e nacionais em torno dos direitos LGBT. Para tanto, nas primeiras seçóes, apresentamos o que denominamos processo de institucionalização do movimento, dando ênfase às parcerias entre Estado 
e os ativistas. Em seguida, a partir da análise da trajetória recente das políticas LGBT, apontamos o que parece ser um declínio nessas políticas e um aumento da oposição, principalmente legislativa, aos direitos LGBT em âmbito nacional. Discutido o contexto nacional, passamos ao caso local, o das políticas LGBT em Campinas. Ao olhar para as relaçóes políticas locais, mostramos um processo parecido de institucionalização do movimento e posterior "desmanche" das políticas, problematizando de que forma um serviço com menor legitimidade política e social, em relação aos demais, atua num contexto de disputa do lugar social da homossexualidade (CARRARA, 2005; FACCHINI, 2012). Apresentado o caso, argumentamos que ele pode ser apontado como um bom exemplo local para entender o impacto do avanço de uma agenda política contrária aos direitos LGBT no Brasil, demonstrando-se, assim, como um caso paradigmático no que diz respeito às disputas em torno da legitimidade das políticas LGBT no país.

No que tange à trajetória, às relaçóes com o Estado e à institucionalização do movimento LGBT em âmbito nacional, temos como base bibliografia sobre o tema preocupada com tais questóes (RODRIGUES, 2014; FACCHINI, 2005, 2009, 2012; SIMÔES, FACCHINI, 2009; DANILIAUSKAS, 2011; CÂMARA, 2002; CARRARA, 2010). No que diz respeito ao processo local, a discussáo baseia-se em trabalho de campo dos autores realizados em pesquisas de iniciação científica, ambas preocupadas com o Centro de Referência LGBT de Campinas (CR) e realizadas no Pagu - Núcleo de Estudos de Gênero da Unicamp. Tais pesquisas analisaram o Centro de Referência em dois aspectos. A primeira tinha por objetivo inferir sobre as relaçóes entre movimento LGBT e Estado, através do Orçamento Participativo (OP), que resultaram na criação e implementaçáo do, então, Centro de Referência GLBTT de Campinas. ${ }^{1}$ A segunda procurava compreender o Centro de Referência em sua fase atual, sua rede de acolhimento e encaminhamento das denúncias. Além dessas pesquisas de iniciação científica, parte das reflexôes deste artigo se deram a partir do desenvolvimento dessas discussóes nas pesquisas de pós-graduaçáo dos autores. ${ }^{2}$

No que concerne à compreensão dos movimentos sociais, fundamentada em discussôes feitas por Facchini (2005), este artigo tem como importante base teórica apontamentos de Doimo (1995) e Cardoso (1987). Essas autoras reiteram a importância da análise dos contextos em que estáo inseridos os movimentos sociais para melhor compreensão da modalidade de ativismo que se quer estudar. Além disso, enfatizam a importância das relaçóes que esses movimentos estabelecem com outros atores sociais. 


\section{A "terceira onda" e a intensificação das relações com o Estado}

O período denominado por Facchini (2005) de "terceira onda”, ou ainda de "reflorescimento", tem início nos anos 1990, pouco depois da promulgação da nova Constituição Federal e da retomada de eleições democráticas em todos os âmbitos da política brasileira. Além da redemocratização, esse período é marcado pelas políticas de enfrentamento à epidemia de HIV/Aids no Brasil. Tal epidemia, apesar das tensôes mais características dos anos 1980, gerou forte interlocução entre grupos ativistas LGBT e os governos brasileiros na elaboração e execução de políticas públicas voltadas à prevenção de DST/Aids. É possível pontuar essas primeiras interlocuçóes como o início do processo de constituição dos LGBT enquanto "sujeitos de direitos” no Brasil (RODRIGUES, 2014; DANILIAUSKAS, 2011). Além disso, vale destacar que esse período foi importante para trazer questóes referentes à homossexualidade à esfera pública (FACCHINI, 2005; SIMÓES, FACCHINI, 2009; DANILIAUSKAS, 2011).

Marcelo Daniliauskas (2011) produziu uma dissertação de mestrado preocupada com a análise da trajetória de questóes LGBT no âmbito das políticas de Direitos Humanos no Brasil, focando sua análise no Programa Brasil sem Homofobia (BSH). Segundo o autor, "esse programa foi escolhido por ser um marco importante do reconhecimento das pessoas LGBT enquanto sujeitos de direitos" (f. 14) no Brasil. Assim sendo, Daniliauskas apresenta o que chama de antecedentes do BSH, isto é, as primeiras políticas brasileiras voltadas para homossexuais que podem ser vistas como os primeiros passos para a consolidação dos homossexuais enquanto "sujeitos de direito" no Brasil. Retomamos aqui o caminho trilhado pelo autor com o objetivo de situar o processo de institucionalização do movimento LGBT e da intensificação das relaçóes com o Estado.

Dentre os importantes marcos da intensificação da relação entre ativismo e Estado no Brasil, Daniliauskas pontua a entrada em vigor, em 1994, do acordo entre o Brasil e o Banco Mundial conhecido como Aids I. O Aids I, segundo Daniliauskas, "trazia como inovação a participação da sociedade civil na implementação de suas açôes" (f. 43), o que colaborou para a criação de possíveis canais de interlocução entre os governos e grupos da sociedade civil no enfrentamento da epidemia de HIV. Ainda segundo esse autor, durante a governo de Fernando Henrique Cardoso (FHC) (1995 - 2002) o principal agente da interlocução entre Movimento LGBT e Estado foi o Programa Nacional de DST/Aids.

Sob o impacto do convênio entre o Banco Mundial e o governo federal podemos ver a primeira apariçáo oficial do termo "homossexualidade" em 
um documento governamental, no Programa Nacional de Direitos Humanos I (PNDH I), lançado em 1996. A importância desse primeiro aparecimento está na visibilização dessas "pessoas socialmente estigmatizadas", os "homossexuais", que passam agora a ser agentes passíveis do usufruto de direitos. Em outras palavras, o governo federal, ao utilizar o termo "homossexuais" em um documento oficial de garantia de direitos, forja tal populaçáo enquanto "sujeitos de direito" (DANILIAUKAS, 2011).

Seguindo a trajetória da implementação das políticas e documentos aqui apresentados, em 2002 é lançado o Programa de Direitos Humanos II (PNDH II). Nesse documento, o "reconhecimento dos homossexuais como 'sujeitos de direitos' não apenas se mantém, como se aprofunda" (DANILIAUSKAS, 2011, f. 49). Além desse reconhecimento, Daniliauskas aponta como avanço a utilizaçáo, no documento, do termo "orientação sexual". Ademais, chama atenção para a especificaçáo dos "sujeitos de direito", que deixam de ser representados pelo termo "homossexuais", para aparecerem como "gays, lésbicas, travestis, transexuais e bissexuais" (DANILIAUSKAS, 2011, f. 53). Esse segundo documento foi construído através da participação de diversos grupos ativistas LGBT em seminários regionais, atestando a intensificação das relaçôes entre ativistas LGBT e o governo Federal.

Ainda segundo Daniliaukas, no governo de Luís Inácio Lula da Silva (2003-2010), doravante Lula, foram realizadas importantes reformas ministeriais impulsionadas pela relação desse governo com suas "bases" e pelo compromisso em avançar nas questóes sociais. $\mathrm{O}$ autor aponta ainda que uma das preocupações centrais desse governo era o combate às desigualdades baseado em uma política de "diálogo, participação e parceria" (f. 74). Como veremos mais adiante, quando tratarmos das relaçóes entre movimento LGBT e governo municipal em Campinas, essa característica de governos do PT (Partido dos Trabalhadores), pautada no diálogo e que se apresenta como mais aberto para com os movimentos sociais, parece se repetir em âmbito municipal.

No que diz respeito às expressões mais recentes acerca da colaboração entre o Estado e o movimento LGBT, é possível ressaltar, em primeiro lugar, a criação do Programa Brasil sem Homofobia e, em segundo, a realização da I Conferência Nacional GLBT. ${ }^{3}$

O primeiro deles é um documento, lançado em 2004, que, apesar de não ter resultados expressivos no que diz respeito à implementaçáo de políticas públicas, teve grande impacto entre ativistas e na tematização dessas questôes de modo coletivo no âmbito de vários ministérios que nunca haviam se debruçado sobre o tema. No que diz respeito às relaçóes entre Estado e ativismo, "o documento anuncia a parceria entre governo e sociedade civil, na elaboraçâo e implementação do Programa" (DANILIAUSKAS, 2011, f. 91). 
A I Conferência Nacional GLBT foi realizada em 2008, em Brasília, e sua abertura contou com a presença do entáo presidente Lula. Tal conferência foi precedida por versôes regionais e estaduais. "O conjunto das Conferências Estaduais, realizadas entre março e maio de 2008, contou com cerca de 10 mil participantes e resultou num total consolidado de 510 propostas, avaliadas e complementadas na etapa nacional (FACCHINI, 2009, f. 134)". Essa conferência, como argumenta Facchini, é um marco importante para os direitos LGBT no Brasil e para as relaçóes do movimento com o Estado, justamente porque sua realização não seria possível em períodos anteriores, em decorrência do caráter de "tabu" sob o qual era tratada a homossexualidade. Além disso, como ressaltam Facchini e França (2009) e Rodrigues (2014), foi importante também a presença do presidente Lula na abertura do evento. Tal participação representou para alguns dos ativistas o compromisso do presidente com o reconhecimento e encaminhamento de demandas de LGBT.

É importante pontuar ainda que, além de ser relevante na "reaproximação e rearticulação do movimento LGBT com os governos municipais, estaduais e federal" (DANILIAUSKAS, 2011, f. 109), as resoluçôes e propostas aprovadas na I Conferência Nacional GLBT resultaram, em 2009, na criação do Plano Nacional LGBT. Ainda acerca do adensamento das relaçôes entre Estado e movimento, Daniliauskas apresenta, como resultados posteriores ao Plano Nacional LGBT, a criação de uma coordenação geral voltada especificamente para LGBT pela Secretaria de Direitos Humanos da Presidência da República. Além disso, em 2010, é estabelecido o Conselho Nacional de Combate à Discriminação e Promoção dos Direitos de LGBT, tal conselho possui

caráter consultivo e deliberativo, e dentre suas principais atribuiçôes estão nortear as açôes e diretrizes para as políticas de combate à discriminação e à promoção dos direitos de Lésbicas, Gays, Bissexuais, Travestis e Transexuais, assim como monitorar e avaliar o Plano Nacional LGBT. (DANILIAUSKAS, 2011, f. 111)

O que se sobressai nesse processo, portanto, é uma intensificação das políticas estatais que reconhecem os homossexuais enquanto "sujeitos de direito" no Brasil. Tal processo, que tem início nas primeiras apariçóes do termo "homossexuais" e, posteriormente, LGBT, em documentos governamentais, culmina na criação de órgãos e agências estatais voltadas especificamente para questóes LGBT. 
Ainda no que diz respeito às Conferências Nacionais, vale lembrar que, assim como o enfretamento conjunto da epidemia de HIV/Aids, elas tiveram importante papel na fomentaçáo de novos grupos e redes ativistas. Rodrigues (2014), ao discutir o impacto das conferências no Rio de Janeiro, afirma:

No Rio de Janeiro, a conferência foi convocada por decreto do governador em 28 de Fevereiro de 2008. Segundo o decreto, previamente à conferência estadual, nove pré-conferências regionais, abrangendo todos os municípios deveriam ser realizadas com a "finalidade de discutir a interiorização e ampliação da participação do Movimento LGBT local e gestores públicos locais e a eleição de delegados para a conferência estadual'. (f. 29-30, itálico e aspas da autora)

Mais adiante, ela segue:

E assim, um dos objetivos colocados pela organizaçáo, o de fortalecer "redes de articulação e mobilização do movimento social LGBT no estado", parece ter sido logrado. Onde não havia qualquer tipo de movimento organizado, a partir daquele momento, passava a existir (f. 30, aspas da autora).

A partir dos excertos acima apresentados, é possível afirmar que as relaçôes entre ativismo LGBT e Estado causam impacto direto no aumento do número de grupos ativistas LGBT e na institucionalização do movimento no caso local analisado por Rodrigues, isto é, o do Rio de Janeiro.

É importante dizer, ainda, que as relaçóes entre movimento LGBT e Estado avançaram mais nos âmbitos Executivo e Judiciário, estando mais estagnadas no Legislativo. No caso do Executivo, como vimos, a participação tem se dado, principalmente, desde as políticas de enfrentamento ao HIV/Aids, culminando em Planos e Conferências Nacionais contra a discriminação dirigida a LGBT. Atores observados por Rodrigues (2014), na I Conferência Nacional GLBT, apontaram, como uma das principais causas da inércia do Legislativo em relação às políticas dirigidas a essa população, o crescimento do fundamentalismo religioso dentro do Congresso Nacional, afirmação que será repetida pelos gestores LGBT locais dos quais trataremos mais adiante. Essa inércia tem levado tais atores a uma judicialização de suas demandas, visto que o judiciário parece menos avesso que o legislativo no que diz respeito aos direitos de LGBT. 
Algumas das tendências apontadas aqui, no que tange à relação entre Estado e movimento LGBT no Brasil, também são notadas por Pecheny e Dehesa (2011) em sua discussão sobre direitos sexuais e reprodutivos na América Latina. Tais autores argumentam que, da mesma maneira que no processo brasileiro, acordos firmados entre os governos latino-americanos e o Banco Mundial, com o objetivo de combater a epidemia de HIV, tiveram grande impacto no movimento LGBT na América Latina. Esses acordos colaboraram com a intensificação das relações entre ativistas e gestores e técnicos estatais. Acerca de tais relações, Pecheny e Dehesa (2011) afirmam:

En la medida en que estos actores han pasado de una relación de exterioridad al estado y la política (autoritarios) a formas diversas de vinculación con los mismos, muchos han reconocido también el valor de traducir sus reclamos en legislaciones y políticas publicas [...]. Han luchado no sólo por la inclusión de sus demandas en las agendas de deliberación pública y de toma decisiones sino por el derecho de participar en la conformación de los procesos político-formales donde tales agendas se articulan, a nivel tanto nacional como internacional. (p. 39)

Nota-se, desse modo, que a participação crescente dos ativistas LGBT na implementação e avaliação de políticas públicas não é um caso brasileiro isolado. Ademais, Pecheny e Dehesa (2011) argumentam que as políticas de enfrentamento ao HIV/Aids, assim como no Brasil, colaboraram para o crescimento do número de instituiçóes que passaram a se definir como ONGs. Tais autores reiteram, ainda, a relação dessas ONGs com organizaçôes estatais, empresas privadas e outras organizaçóes internacionais.

É possível apontar, ainda, que o aumento das relaçóes com o Estado não é característica única do movimento LGBT no Brasil. Ana Maria Doimo (1995) e Maria da Glória Gohn (1995) sinalizam uma tendência, nos movimentos sociais no Brasil, de aumento de instituições que se concebem enquanto ONGs. Segundo Gohn (1995), além do crescimento desse formato organizacional, se fortaleceram, enquanto tendências, "as políticas de parcerias implementadas pelo poder público, particularmente em âmbito local” (p. 128).

\section{Um processo em declínio}

No que tange à institucionalização do movimento e o avanço da implementação de políticas públicas para LGBT, é importante ressaltar que esse processo parece ter sido crescente até o fim do governo Lula. No entanto, ele começa a entrar em declínio com o governo de Dilma Roussef, tam- 
bém do PT. Tal declínio pode ser exemplificado pela abertura da Segunda Conferência Nacional LGBT, realizada em 2011. A abertura foi marcada, principalmente, pelas críticas à gestáo de Dilma e pelo não comparecimento da presidente (RODRIGUES, 2014).

As críticas, segundo Rodrigues, foram dirigidas ao cancelamento, por parte da presidente, do alcunhado "kit gay", resultado da pressão de políticos religiosos que fizeram intensa propaganda contra o "kit". Esse "kit" era, na realidade, um material educativo a ser distribuído nas escolas do país, e seu objetivo era diminuir os casos de homofobia. Cedendo a pressōes dos políticos religiosos, o "kit" foi retirado de circulação pela presidente sob a alegação de que seu governo não "fazia propaganda de opção sexual". Essa alegação gerou protestos e reclamaçóes de muitos ativistas LGBT em todo o território nacional.

Além da pressão de setores políticos conservadores, que têm crescido substancialmente no país, a outra crítica dizia respeito à ausência da presidente na abertura do evento. Se a presença do presidente Lula ressaltou o compromisso de sua gestáo com as causas LGBT, o náo comparecimento de Dilma foi interpretado por parte dos ativistas, como aponta Rodrigues, no sentido oposto. Essa falta, reforçada pelos retrocessos de seu governo no que concerne às questóes LGBT, fortaleceu a ideia de falta de compromisso com o movimento social organizado em torno de tais questóes.

Além da retirada de circulação do "kit gay", outros sinais dos avanços de um conservadorismo político pautado, entre outras coisas, em valores que se opóem a políticas de direito para LGBT podem ser apontados. Dentre eles ressaltamos um projeto que ficou conhecido como "cura gay", além de falas abertas contra homossexuais proferidas por políticos brasileiros.

O projeto de "cura gay", um Decreto Legislativo proposto pelo deputado federal Joáo Campos, do PSDB (Partido da Social Democracia Brasileira), tinha por objetivo suspender a validade da resoluçáo 001/99 de 22 de março de 1999 do Conselho Federal de Psicologia (CFP), que impede os psicólogos de tratarem a homossexualidade como desordem psicológica. A aprovação pela Comissáo de Direitos Humanos (CDH) da Câmara dos Deputados, em 2013, àquela época presidida pelo pastor e deputado Marco Feliciano, colocaria o projeto em trâmite no Congresso para possível votação.

Apesar de a resoluçáo do CFP que veda o tratamento dos homossexuais enquanto pacientes a serem curados ser de 1999, desde 1985 a homossexualidade deixou de ser considerada doença no país. Contudo, a aprovação na Comissão de Direitos Humanos do projeto que foi chamado de "cura gay" criaria uma nova possibilidade de patologizaçáo da homossexualidade, agora por via legislativa. É importante ressaltar que, no dia 2 de julho 
de 2013, o autor do projeto em questão retirou sua proposta. Alguns dias depois, no entanto, outro deputado reapresentou o projeto.

Gostaríamos de salientar, também, ataques mais recentes ao processo, ainda em curso, de constituição de LGBT enquanto sujeitos de direito no Brasil, como a retirada das discussóes de gênero e diversidade sexual do Plano Nacional de Educação. Além de tentativas recentes do legislativo de aprovar projeto de lei que segue na contramáo das decisóes judiciais de permitir o casamento entre pessoas do mesmo sexo, intitulado "estatuto da família". ${ }^{4}$ Diferentemente das decisōes judiciais, o texto do estatuto prevê que uma família é formada unicamente pela uniáo de um homem e uma mulher.

Além dos projetos em questão, é possível destacar a publicização de discursos contra políticas LGBT por políticos brasileiros. Dentre eles, destacamos o deputado e pastor Marco Feliciano e o deputado Jair Bolsonaro, do PP (Partido Progressista). No caso do primeiro, sua nomeaçáo para ocupar a chefia da $\mathrm{CDH}$ foi alvo de contestaçóes não apenas por parte de ativistas LGBT, mas também de militantes do movimento negro, por exemplo. Essa contestação baseava-se em discursos, proferidos por tal deputado, considerados racistas e homofóbicos. Assim como no caso de Feliciano, Bolsonaro é alvo de críticas náo só provenientes do movimento LGBT, mas também de feministas e outros atores preocupados com os direitos humanos. O motivo das críticas é sua oposição aos direitos humanos, em geral, além de seu apoio à Ditadura Militar.

Até aqui nos detivemos sobre a trajetória e o processo de institucionalizaçáo do movimento LGBT em âmbito nacional. Deu-se especial atençáo ao aumento substancial de políticas no decorrer dos anos 1990 e início dos anos 2000, referentes às gestóes federais de FHC e Lula. Em seguida, apontamos que parece haver uma diminuição das políticas e um aumento da oposição pública aos direitos de LGBT em período recente.

Feito isso, passemos agora ao aprofundamento da análise de um contexto localizado.

\section{Uma breve incursão sobre o surgimento dos coletivos LGBT em Campinas}

O primeiro coletivo de caráter explicitamente político que se tem notícia a discutir a homossexualidade em Campinas, o grupo Expressão, surgiu em 1995. Esse grupo, assim como as demais organizaçóes ativistas de Campinas que emergiram posteriormente, integra o processo de crescimento, de expansão territorial e de interiorização do movimento que caracteriza o período denominado por Facchini (2005) de "terceira onda" do movimento LGBT brasileiro (ZANOLI, 2015). 
Em 1998, a partir de uma cisão interna do Expressão, surgiu o Identidade, o grupo ativista LGBT mais antigo em atividade na cidade de Campinas. Divisóes posteriores do Identidade deram início a dois outros grupos da cidade: Mo.Le.Ca. (Movimento Lésbico de Campinas), fundado em 2000, e o Aos Brados!!, grupo ativista LGBT que discute questóes ligadas à periferia e à negritude, criado em 2002. Além desses grupos, os anos 2000 viram nascer uma inciativa do movimento LGBT sem vínculo anterior com as demais, o E-Jovem, uma rede jovem LGBT presente em diversos estados brasileiros, fundada em 2004 (ZANOLI, 2015). ${ }^{5}$

Todos esses grupos têm seu surgimento no período citado acima, denominado por Facchini (2005) de "terceira onda", ou "reflorescimento" do movimento LGBT. Além das características já referidas, outro marco do "reflorescimento" é o aumento das parcerias estabelecidas entre governos, em seus diversos níveis, e as diversas organizaçóes que integram o movimento LGBT.

\section{Institucionalização e a implementação de políticas municipais para LGBT}

Em 2001, com a posse do novo prefeito eleito no ano anterior, Toninho do PT, tem início o processo de criaçáo do Orçamento Participativo (OP) de Campinas. No modelo escolhido pela administraçáo municipal, o OP seria composto por um conselho com representantes da sociedade civil.

Tal conselho era dividido em eixos temáticos e em quatorze regionais. Os eixos temáticos eram os seguintes: saúde, assistência, cidadania, cultura e esporte, desenvolvimento econômico, educação e gestão. Algumas dessas temáticas eram divididas, ainda, em categorias ou subcategorias.

Wampler (2008, p.67) define o Orçamento Participativo brasileiro como

uma instituição participativa de amplo alcance, cuja iniciativa coube a governos municipais e a ativistas da sociedade, movidos pela esperança de criar processos orçamentários públicos, abertos e transparentes, que permitissem aos cidadáos se envolverem diretamente na seleção de resultados específicos de políticas públicas.

Esse tipo de ferramenta de gestão participativa foi utilizado pela primeira vez por um governo do PT, na prefeitura de Porto Alegre, capital do Rio Grande do Sul, no ano de 1989 (AVRITZER, 2003). Mais de dez anos antes de ser utilizado por uma gestão, também petista, em Campinas. Apesar de ter sido inaugurado no Brasil pelo PT, no período entre 1989 
e 2004, todas as cidades com mais de cem mil habitantes adotaram o OP, sejam elas governadas ou não pelo PT (WAMPLER, 2008). Além disso, Wampler chama atenção para o fato de que "por volta de 2001, praticamente dois terços das novas adoçóes do OP ocorriam em cidades que não eram administradas pelo PT" (WAMPLER, 2008, itálico do original).

Ainda que cidades administradas por outros partidos políticos tenham implementado OPs em suas administrações, é importante retomar as observaçóes de Daniliauskas (2011) sobre a importância de levar em conta a relação entre o PT e movimentos sociais nos anos 2000, bem como sua ênfase na participação política para compreender o modo como políticas públicas e mecanismos de gestão participativa são implementados. Tanto a criação do $\mathrm{OP}$ em Porto Alegre quanto sua versão campineira e a realização das Conferências Nacionais LGBT podem ser analisadas a partir desse ângulo que vê, no partido, uma preocupação política com a relação com suas bases, ao menos até o fim do governo Lula.

Retomando o caso campineiro, apesar de ser uma política participativa pautada nos movimentos sociais, um deles havia ficado de fora, o movimento LGBT. Em decorrência disso, os ativistas deram início a uma intensa mobilização local para que a questão LGBT e as demandas do movimento organizado fossem alocadas no OP. A denominada luta pela inclusão dos homossexuais no OP teve êxito, e essa inclusão se deu a partir do eixo temático dedicado a questóes de cidadania. Dessa maneira, os homossexuais dividiam esse eixo com negros, idosos, jovens, portadores de deficiência e mulheres, cada um desses grupos escolhia seu representante para compor o conselho da cidadania do OP.

Com a alocação dos homossexuais na temática cidadania do OP, o movimento ficou incumbido de escolher um conselheiro para representar a causa na cidade. $\mathrm{Na}$ votação para os representantes, membros da sociedade civil organizada escolhiam uma das temáticas ou subtemáticas com a qual se identificavam. Após a escolha, indicavam quem desejavam que fosse seu representante no conselho do OP. Fernanda, que editava o jornal Aos Brados, foi a escolhida para representar o movimento LGBT no conselho.

Uma vez implementado o OP, representantes do movimento LGBT apresentaram sua primeira proposta: a criação de um Disque-Defesa Homossexual (DDH) que recolheria denúncias de homofobia. No ano seguinte, em 2002, esse projeto foi aprovado e, como resultado das negociaçôes do movimento com a Secretaria de Assuntos Jurídicos (SAJ) da cidade - órgão responsável pela criação do serviço proposto ao $\mathrm{OP}$-, os representantes do movimento LGBT, depois de alguma disputa, indicaram um ativista do grupo Identidade para coordenar o serviço, Lucas.

Ainda entre os anos de 2001 e 2002, os representantes do movimento 
LGBT de Campinas se reuniram no Museu de Imagem e Som (MIS) para discutir os projetos que seriam apresentados ao OP. Depois de aprovado o Disque-Defesa Homossexual, as discussóes giravam em torno da proposição de um Centro de Referência LGBT e da indecisão em relação ao lugar do DDH caso o CR fosse aprovado: se seria um serviço separado ou se passaria a integrar os serviços prestados pelo Centro de Referência LGBT.

Ainda em 2002, o movimento LGBT apresentou ao OP o projeto, aprovado no mesmo ano, de criaçáo do CR, que ofereceria assistência social, jurídica e psicológica a LGBT. A escrita do projeto envolveu ativistas do Identidade, do Mo.Le.Ca., o fundador do E-Jovem e ativistas que, mais tarde, fundariam o Aos Brados!!. As discussóes realizadas no MIS levaram a certo consenso sobre a importância do $\mathrm{CR}$ e, em consequência disso, os ativistas elegeram a proposição do serviço como prioritária, fazendo com que os ativistas apresentassem o projeto ao OP sob o título "Prioridade № 1”. Ressaltando que, do conjunto de projetos enviados ao OP, aquele deveria receber especial atenção.

É importante aqui um rápido parêntese para ressaltar algo de interessante acerca do processo de implementação do CR. Apesar de inaugurado em 2003 - antes mesmo do lançamento do BSH, lançado em 2004 e que tinha como um dos objetivos fomentar esses centros - a existência formal dessa política pública só foi regulamentada no ano seguinte, a partir do decreto municipal no 14.787, de 28 de junho de 2004, que aloca o CR "junto à Coordenadoria de Proteçáo Especial, do Departamento de Cidadania, da Secretaria Municipal de Assuntos Jurídicos e da Cidadania". ${ }^{6}$ Mesmo que em âmbitos distintos, a implementaçáo e realização de políticas antes de sua existência legal foi notada por Daniliaukas (2011), na criação do programa Brasil sem Homofobia. Embora o BSH tenha sido lançado em 2004, foi apenas depois de 2009 que uma coordenação formal foi criada para o programa.

Apesar da aprovaçáo do projeto CR, no mesmo ano em que foi enviado ao OP, segundo os entrevistados, a implementaçáo do CR foi demorada, o que desgastou as relaçóes dos ativistas com o Estado. O principal ponto de tensão foi a demanda do movimento por indicar todos os funcionários da nova política. Na negociaçáo, o movimento pôde indicar a advogada, que era integrante do Mo.Le.Ca. Além disso, Lucas, o coordenador do DDH, se tornou também coordenador do CR, o que resultou na incorporação do $\mathrm{DDH}$ à nova política. Os demais funcionários foram contratados através de edital da prefeitura.

Um dos motivos da incorporaçáo do DDH pelo CR foram duras críticas dirigidas pelos ativistas à Guarda Municipal (GM) de Campinas. Anteriormente à incorporação pelo $\mathrm{CR}$, as denúncias do $\mathrm{DDH}$ eram recebidas 
pela GM, vista como despreparada para recebê-las, desmotivando a procura de ajuda numa situação de discriminação e/ou violência. Atualmente, no entanto, fortes críticas são feitas pelo movimento no sentido de que, apesar do DDH náo estar mais ligado à GM, a Guarda ainda possui acesso aos protocolos de denúncia, deixando os usuários do serviço desprotegidos ao realizarem uma denúncia contra a GM.

Além das dificuldades na implementaçáo do serviço, o Centro de Referência passou também por diversas mudanças de nomenclatura e realocaçóes na estrutura organizacional da prefeitura: criado em 2003 e subordinado à Secretaria de Assuntos Jurídicos, o CR passou a responder à Secretaria de Cidadania, Trabalho, Assistência e Inclusão Social, em 2005, devido à eleição de Hélio de Oliveira Santos, do PDT, à prefeitura municipal. Em 2007, com uma nova reforma administrativa, o Centro de Referência foi transferido para a Secretaria de Assistência, Cidadania e Inclusão Social (SACIS), que, na nova pasta, deixou de incorporar "Trabalho". Nesse mesmo período, ocorria a implementação do SUAS (Sistema Único de Assistência Social) em todo o país, o que transformou o CR em CREAS-LGBT (Centro de Referência Especializado de Assistência Social de Lésbicas, Gays, Bissexuais, Travestis e Transexuais). No fim de 2012, contudo, o serviço perdeu o status de CREAS e voltou a ser denominado, apenas, Centro de Referência LGBT. A partir de 2013, o CR continuou fazendo parte da SACIS, porém realocado no Setor de Apoio às Políticas Públicas Sociais.

Além da implementação do Centro de Referência LGBT de Campinas e do Disque-Defesa Homossexual, ressaltamos, como resultados das relaçôes entre o movimento LGBT e o governo municipal, duas políticas implementadas na cidade, a Lei Municipal no 9.809, de 28 de julho $1998^{7}$ e a Portaria $\mathrm{n}$ - 6, de 19 de de novembro de $2004 .^{8}$ A primeira é uma Lei Municipal que combate todas as formas de discriminação. A segunda é uma portaria que instaura um protrocolo de redução de danos voltado a usuários de silicone industrial e hormonoterapia, que visam atender principalmente, mas não somente, travestis e transexuais. Ambos são resultados da interlocução direta entre o movimento da cidade e do governo municipal.

Se os primeiros anos da década de 2000 podem ser apontados como profícuos no que diz respeito à interlocução entre movimento e Estado em Campinas na criação e implementação de políticas para LGBT, o fim dessa década e o início da subsequente nos revelam um "desmanche" das políticas municipais voltadas para essa populaçáo, como veremos a seguir. 


\section{"Desmanche" das políticas locais}

$\mathrm{Na}$ época de sua implementação, o Centro de Referência iniciou suas atividades com parte de seu quadro de funcionários vinda do ativismo (coordenador e advogada), complementado por quadros da Prefeitura (recepcionista, psicóloga, assistente social e serviços gerais). A equipe, até meados de 2014, contava com um assistente social, um psicólogo, um secretário, um auxiliar em serviços gerais e um advogado. Esse último cargo voltou a ser preenchido há pouco tempo, tendo o serviço ficado muito tempo sem advogado. Não muito tempo depois, no entanto, o CR voltou a ter o cargo de assessoria jurídica vacante.

A falta de um profissional da área jurídica na equipe foi justificada pelos outros funcionários como um histórico de insucessos. Após a saída da primeira advogada, vinda do movimento social, o serviço encontrou dificuldade de fixar um profissional. A primeira advogada foi substituída por outro, indicado pela prefeitura, que segundo os gestores do serviço náo compreendia as especificidades do público atendido pelo $\mathrm{CR}$, seus atendimentos incorreram em diversas reclamaçóes de usuários do serviço, acabando por ser substituído. $\mathrm{O}$ advogado que assumiu sua posição, também advindo dos quadros municipais, foi exonerado em 2012 por motivos desconhecidos, prejudicando o atendimento jurídico no serviço. Segundo a coordenadora do CR, nenhuma informação constando os motivos da exoneração de tal advogado foi passada ao centro, o que fez com que o serviço encerrasse, por tempo indeterminado, um de seus pontos centrais de atuação, a assessoria jurídica. Ainda no fim de 2012, com o aparente término da crise política da cidade de Campinas, um servidor municipal e ativista do grupo Identidade transferiu-se de seu cargo para oferecer serviços de assessoria jurídica aos usuários do $\mathrm{CR}$, uma vez que também era formado em direito.

Além disso, Lucas, que, como apontando anteriormente, coordenava o Centro de Referência, manteve-se em seu cargo até janeiro de 2010, quando assumiu a então recém-criada Coordenadoria de Políticas para a Diversidade Sexual (CPDS). O cargo de coordenador do CR foi assumido por Mara, a assistente social, que acumulou as duas funçóes, o que denota fragilidades na equipe. Essas fragilidades impactam o funcionamento do serviço, com funcionários desdobrando-se em diferentes funções, competências e horários. Os impactos dessa fragilidade puderam ser acompanhados durante realização do trabalho de campo.

Pudemos acompanhar diversas atividades realizadas aos fins de semana e à noite, fora do horário de expediente dos funcionários. Estivemos presentes também em atividades de formação de professores, realizadas por 
Júlio e Clara, o advogado e a psicóloga do CR, respectivamente, em escolas da rede pública. Tais atividades, muitas vezes, acabavam muito depois das dezessete horas, que deveria ser o fim do expediente dos funcionários. Clara, além de realizar atendimentos psicológicos na sede do centro, atua como formadora em escolas da regiáo, sob demandas das próprias escolas ou de seus pacientes, além de manter um grupo com os usuários transexuais do serviço, geralmente realizado aos fins de semana. Júlio, por sua vez, devido à alta demanda de atendimento jurídico, acabava, diversas vezes, por trabalhar muitas horas a mais do que o previsto por sua contratação. Ademais, presenciamos a coordenadora do CR trabalhando nas férias para que um evento que pretendia organizar acontecesse. A atuação dos funcionários, portanto, ia além de oferecer os atendimentos preconizados pelo serviço. O planejamento do serviço procurava intervir socialmente, o que implicava que a equipe de atendimento acrescentasse a suas atividades o que, em outros contextos, é realizado por ativistas ou consultores contratados.

Cabe mencionar ainda que, pouco tempo depois da posse do novo prefeito da cidade, Jonas Donizette, do Partido Socialista Brasileiro (PSB), em 2013, a CPDS passou a existir apenas oficialmente, carecendo de um coordenador. Tal ocorrido levou a coordenadora do $\mathrm{CR}$ a não apenas atuar em suas duas funçôes no serviço (gestora e assistente social) como também a assumir algumas das obrigaçóes do responsável pela CPDS, como a organizaçáo de reuniôes com o movimento LGBT local, a organização das Conferências Municipais LGBT, dentre outras funções.

Apesar dessa fragilidade, a equipe do Centro de Referência mantém alguma articulação com outros atores, utilizando-se das redes de referência municipais para estabelecer parcerias, refazendo-as, ou não, a cada mudança no organograma municipal. Como notamos, parece haver uma fragilização da política como um todo, principalmente no que diz respeito à falta de funcionários para atuar no serviço. Essa fragilidade acabou se acentuando em decorrência da crise política que atingiu o município em 2011.

Naquele período, a cidade vivia uma grave crise política, deflagrada após um acordo de delação premiada entre Luiz Augusto Castrillon de Aquino, ex-presidente da Sociedade de Abastecimento de Água e Saneamento (SANASA) e o Ministério Público, que revelou detalhes de um suposto esquema de corrupçáo da empresa. Consequentemente, o poder público do município passou a viver um clima de grande instabilidade política, marcado por uma série de denúncias, escândalos e pedidos de impeachment, o que ocasionou a troca de prefeito três vezes no período de um ano. Servidores, dentre eles funcionários do CR, relataram que consultavam todos os dias o Diário Oficial para descobrirem se estavam 
empregados ou náo, fato ocorrido com a penúltima advogada do Centro de Referência, que descobriu sua exoneraçáo no meio de um expediente de trabalho através do Diário Oficial (FALCÃO, 2012, p. 14).

O "troca-troca" de cadeiras nos diferentes níveis de hierarquia da Prefeitura Municipal de Campinas teve impacto direto nas relações do CR, em especial as parcerias com os outros órgãos municipais, pois a cada novo prefeito ocorria também a mudança de secretários e demais cargos de confiança, exigindo do Centro de Referência a repactuaçáo constante das parcerias. Entretanto, importante mencionar que essa prática de repactuação já ocorria, devido às diferentes gestóes e mudanças no organograma da cidade, acentuando-se no cenário político instável da crise municipal, visto que essas repactuaçóes deixaram de ocorrer apenas a cada quatro anos.

Essa mudança de organograma municipal pode ter afetado mais o CR do que outras políticas, em decorrência de sua menor visibilidade como política municipal. Desse modo, sempre que um novo prefeito era escolhido, era preciso entrar em contato com alguns dos órgãos municipais, reiterando a existência do serviço e as demandas que o CR era capaz de atender.

Gestores e outros atores ligados à política LGBT na cidade levantaram, durante a realização do trabalho de campo, preocupação com o aumento do conservadorismo político na cidade, principalmente resultado do maior número de vereadores eleitos em 2012 ligados à bancada religiosa (PORTAL RAC, 2012). Ademais, diversas vezes em campo, ouvimos a palavra desmanche para situar o atual estado do CR.

Desmanche, nesse contexto, é compreendido como analogia ao desmanche de carros, em que algumas peças são retiradas, desfigurando e debilitando o automóvel, porém não o suficiente para chegar ao ponto de não ser identificado como um carro. Tal ideia pode ser aplicada em uma análise das políticas locais. Falta de advogados, funcionários com múltiplos cargos e horários além do expediente são as peças "faltantes", porém, como o automóvel, não são "faltantes" o bastante para tornar o serviço não identificável. Assim, através da ideia de "trama institucional", percebemos as relaçôes de poder na rede municipal e como o CR sustenta-se nesse complexo contexto, em que a própria legitimidade de uma política voltada para LGBT pode estar em xeque.

O conceito de "trama institucional", assim como cunhado por Gregori (2000), fornece base teórico-metodológica para compreender a complexa rede formada por diversos atores com diferentes inserçóes nos mais variados níveis de hierarquia. Sob uma perspectiva processual, tal noção nos permite tornar visíveis as relaçóes entre diferentes atores e seus impactos nas potencialidades e dificuldades acerca da implementaçáo e manutenção da política pública responsável pela criação do Centro de Referência. A 
partir dessa concepção compreendemos como o CR é afetado pelas relaçóes em sua trama.

O "desmanche" de que falam nossos interlocutores é elucidativo de uma espécie de processo similar àquele ocorrido em âmbito Nacional. Esse "desmanche" não envolve apenas o Centro de Referência, mas outras políticas municipais, como a Lei Municipal no 9.809, de 28 de julho 1998, citada acima. O decreto de regulamentação dessa lei previa a criação de uma Comissão Processante que seria responsável pela apuração dos atos discriminatórios e pela aplicação das penalidades previstas na Lei. Mesmo sendo de 1998, foi apenas em 2012, depois de muita pressão do movimento, que tal comissão foi finalmente instaurada pela Portaria $\mathrm{n}^{\mathrm{o}} 77.823 / 2012$. $^{9}$

Além disso, podemos apontar, como exemplo de uma oposiçáo por parte do legislativo municipal aos direitos LGBT, a aprovação em primeiro turno de uma emenda à Lei Orgânica do Município que proíbe projetos de lei que incitem discussóes em torno de direitos sexuais e reprodutivos, ou que façam menção às palavras gênero e diversidade sexual. Projeto que está diretamente ligado ao pânico moral (WEEKS, 1985) em torno da chamada "ideologia de gênero", que levou termos como gênero e diversidade e orientaçáo sexual a serem excluídos do Plano Nacional de Educação (FACCHINI, 2015) e a posteriores exclusóes nos planos municipais.

A situação analisada no município guarda semelhanças com o que Gregori (2000) apresenta em seu estudo sobre meninos em situaçáo de rua, com a "reconstruçáo da história recente do que se passou em São Paulo na tentativa de aplicar o Estatuto da Criança e Adolescente, com seus inegáveis avanços na legislação" (ZALUAR, 2001). Gregori também narra a fragmentação da política social voltada para crianças e adolescentes. $\mathrm{Na}$ época de seu estudo, a questão dos meninos em situaçáo de rua tornou-se "uma imensa arena de disputas de diversas naturezas, impedindo açóes que [viessem] a resultar em soluçóes mais efetivas a longo prazo" (GREGORI, 2000, p. 161). Algo semelhante ocorre com a questáo LGBT no contexto em que o CR de Campinas está inserido. Contudo, é a legitimidade social e política dos sujeitos a que se destinam as políticas que diferencia o CR das políticas analisadas por Gregori.

A análise de Gregori sobre meninos em situação de rua correspondia a uma demanda imediata e concreta relacionada a crianças que, além de amparadas pela nova compreensão estabelecida pelo ECA (Estatuto da Criança e do Adolescente), estavam expostas nas ruas da cidade, exigindo açóes concretas: alimentar, abrigar, fornecer documentação, reintegrar à família. Além disso, os meninos eram claramente vistos, na época do estudo, como expoentes da desigualdade social.

No caso da população LGBT, não só a demanda não é tão claramente visível como também o reconhecimento social e político dessa parcela da 
população como sujeitos de direitos está no próprio centro de uma complexa arena de disputas. Nesse contexto, tanto a populaçáo LGBT quanto os serviços a ela destinados precisam disputar cada prática institucional cotidianamente e seu espaço nas diferentes relaçóes da trama institucional que se forma.

Como ocorreu com os meninos e meninas em situação de rua, os usuários do CR negociam com o serviço, assim como o serviço negocia com seus usuários. Em algumas ocasióes, proporcionadas por visitas de campo, foi possível observar, durante uma oficina oferecida pelo CR, que cestas básicas eram entregues mediante participação no evento, operando como incentivo para a adesão às atividades, como ocorria com os meninos de rua no estudo de Gregori. Nessa mesma oficina, os funcionários do Centro de Referência ressaltavam aos usuários a relevância de que ao acessar algum outro serviço do município era importante informar que a indicação ocorreu via CR. Tal orientação visa garantir que a própria população atendida contribua para a legitimaçáo do serviço, demonstrando que existe uma demanda de uma populaçáo que procura e utiliza o Centro de Referência.

Essa importância da demanda se expressa também em outra situação observada no CR, no ano de 2012. Acompanhávamos uma oficina de papel machê; nela, um dos usuários do serviço perguntou à psicóloga sobre a possibilidade de contratação de um novo advogado, em decorrência da exoneração do anterior. Em resposta, a psicóloga disse que ela e a coordenadora do CR estavam engajadas para tal, mas que precisavam da ajuda dos usuários, afinal, era para eles que os serviços eram oferecidos. Desse modo, ressaltou a importância de que os usuários ligassem para o "156", serviço telefônico de relação entre os cidadãos e a prefeitura, e registrassem reclamaçóes formais quanto à falta de um advogado no serviço. Nessa fala, a importância de que essas pessoas reiterassem seu caráter de "usuários do serviço" foi ressaltada. Afinal, segundo a coordenadora do CR, as relaçóes dela e da psicóloga, enquanto gestoras, não possuíam o mesmo potencial que queixas provenientes de cidadãos que utilizam o serviço público.

Em sua análise das instituiçóes e políticas públicas criadas a partir do ECA, Gregori (2000) demonstra que tais políticas não eram integradas e que os menores náo eram atendidos num circuito em que realmente conseguiriam mudar suas perspectivas de futuro, sobretudo porque continuavam a ser tratados como simples objetos e não como sujeitos de direitos. Ao analisar o contexto do CR e seus usuários, verifica-se que os LGBT são vistos pelos funcionários do serviço náo só como objetos de ações, mas também como sujeitos que buscam direitos. No entanto, no caso do CR, é o serviço e a populaçáo para a qual atua que não contam com suporte e legitimidade social e política. Para os outros atores, que não os funcionários 
do serviço e o movimento social, a possibilidade de enxergar LGBT como "sujeitos de direito" pode ser bastante remota. Compreender as estratégias utilizadas para manter o Centro de Referência funcionando, no atual contexto da cidade e das disputas acerca do lugar social da homossexualidade (CARRARA, 2005) no Brasil, nos permite perceber os pontos de disputa e as alianças firmadas na trama institucional da cidade.

Essas disputas se manifestam no discurso da coordenadora do CR, ao relatar que as alianças e relaçóes precisam ser repactuadas diariamente, precisam ser lembradas para estarem presentes; e que em determinados momentos é necessário apelar aos usuários do serviço, fazendo-os mostrar que o CR funciona e possui a demanda necessária para se manter ativo.

$\mathrm{O}$ papel do movimento social não deve ser desconsiderado na manutenção da existência do CR. É preciso entender que o movimento social vê o Centro de Referência como a expressáo da sua participaçáo e luta política no município, como um espaço de conquista no jogo político local. No entanto, é fundamental perceber e situar o CR num campo de atuação em que é necessário agir de maneira comedida, garantindo o sustento e permanência na atual trama.

Ainda no que diz respeito ao tênue equilíbrio a ser mantido pelo executivo local na arena de disputas acerca do lugar social da homossexualidade, o relato de Lucas é bastante elucidativo: "A prefeitura precisa fazer políticas LGBT para não apanhar do movimento, porém essa política não pode ter visibilidade para não apanhar do lado conservador". Dessa maneira, se por um lado o serviço se mantém ativo sob pressão do movimento social em relação a prefeitura, estratégias como a falta de sinalização da entrada do prédio são essenciais para que a grande parcela conservadora do município não conteste a legitimidade de um serviço voltado para uma população que, ainda hoje, é vista por muitos como doente e/ou pecaminosa (RUBIN, 1984; FRY, 1982).

\section{Considerações finais}

Neste artigo, apresentamos, primeiramente, a trajetória de institucionalização do movimento LGBT brasileiro, dando ênfase ao aumento da interlocução entre essa modalidade de ativismo e o Estado, principalmente no que diz respeito à proposiçáo e implementação de políticas públicas. Em seguida, procuramos demonstrar, a partir da literatura e acontecimentos políticos recentes que mobilizam direitos LGBT, que se o processo de institucionalização e de promoção de políticas públicas se apresenta como crescente até meados da primeira década dos anos 2000, após esse período esse processo passa a estagnar. 
Apresentado o contexto nacional, partimos para a análise de um contexto local, foco de nossas pesquisas, o das políticas para LGBT na cidade de Campinas, no estado de Sáo Paulo. Ocupamo-nos, desse modo, em situar os diferentes atores - em especial Movimento e Estado - relacionados a partir do OP no processo de criaçáo do CR. Contextualizando, dessa maneira, o cenário local das políticas em torno dos direitos de LGBT nas primeiras décadas dos anos 2000. Em seguida, discutimos a atual configuração das relaçóes dos gestores do $\mathrm{CR}$, não só com o movimento social que o criou, mas também com os demais gestores municipais, situando também os impactos dessas relaçóes na política em questáo. Desse modo, analisamos de que forma um serviço com menor legitimidade política e social, em relação aos demais serviços municipais, atua num contexto de disputa do lugar social da homossexualidade entre diversos atores sociais, como o movimento social e políticos municipais.

Tal disputa acerca do lugar social da homossexualidade impacta fortemente na fragilidade do serviço em questão. Ao nos referirmos à homossexualidade como um lugar social, estamos chamando atençáo para o fato de que o significado das relaçóes sexuais consideradas não heterossexuais é uma arena em disputa, ou seja, se para o movimento em questáo a homossexualidade envolve prazer e desejo, para outros sujeitos políticos ela diz respeito a pecado e doença (CARRARA, 2005). Essa segunda noção, hegemônica, acaba por alocar pessoas que se compreendem ou são compreendidas como não heterossexuais em posiçóes sociais inferiores (RUBIN, 1984), dificultando assim a existência de um serviço que visa oferecer direitos básicos a essa populaçáo.

Assim sendo, levando a sério a categoria êmica "desmanche", buscamos conectar as discussões feitas no artigo entre o contexto local e o contexto nacional. Desse modo, assim como no caso de políticas federais, a disputa em torno do lugar social da homossexualidade parece ter impactado fortemente na manutenção das políticas conquistadas no início dos anos 2000. Esse contexto local se apresenta muito diverso daquele encontrado por Rodrigues (2014), por exemplo, ao atentar para a implementaçáo de políticas focalizadas para LGBT no Rio de Janeiro, onde a atuação do movimento local e suas demandas parecem ter gerado políticas públicas e o fortalecimento da relaçáo com o Estado, inclusive fomentando a criação de novos grupos.

Em Campinas, a despeito da criatividade e do pioneirismo da ação dos ativistas, nota-se considerável precariedade das políticas que foram implementadas e do reconhecimento de LGBT como sujeitos de direitos. O movimento, em sua ansiedade por respostas, demandava um serviço, o CR, que cumprisse também funções de gestão. O serviço foi implementado, 
porém, além de não poder atuar como articulador de políticas nas várias secretarias, seus funcionários, não raro, acumulam funções e/ou trabalham para além do horário contratado e precisam, o tempo todo, reafirmar e buscar legitimar a necessidade de sua existência. Anos depois, cria-se um órgão de gestão, uma coordenadoria, que não tem mais do que um funcionário contratado, nem alocação clara no organograma da cidade que lhe permita articular políticas para LGBT. Uma lei antidiscriminatória foi aprovada, mas não podia ser utilizada por falta de uma Comissão Processante formalizada. A exoneração de Lucas da CPDS e a vacância de seu cargo, que já dura mais de dois anos, são importantes marcas de uma política LGBT fragilizada.

Portanto, levando-se em consideraçáo o que se discutiu nas primeiras seçôes deste artigo, acreditamos que o caso de Campinas seja elucidativo do que vem ocorrendo com as políticas LGBT no Brasil. Ainda que exista um processo de implementação de algumas políticas, como é o caso do $\mathrm{BSH}$, elas trouxeram poucos resultados concretos, ao que se soma muita resistência em forma de projetos de lei que visam barrar o processo, ainda em curso, da constituiçáo dos LGBT enquanto sujeitos de direito. Essa falta de resultados está diretamente ligada à emergência dos direitos de LGBT como uma intricada arena de disputas, o que impacta a legimitidade e a existência de serviços e políticas direcionados a essa população.

\section{Notas}

1. No decorrer da história do CR, seu nome passou por algumas modificaçôes. Decidimos manter a nomenclatura original quando nos referirmos ao período em que o centro assim era denominado.

2. Em momentos distintos, as pesquisas em questão receberam apoio financeiro do SAE/Unicamp, do CNPq e da FAPESP.

3. Assim como os diversos autores que tratam da I Conferência Nacional GLBT, mantivemos a grafia do termo "GLTB", em vez de utilizar o termo "LGBT", escolhido na I Conferência para dar visibilidade às lésbicas. Ainda que a utilização de siglas distintas possa confundir o leitor, a manutenção dos termos no original é importante pois expressa o período a que a sigla se refere.

4. Para mais informaçóes acerca das decisóes judiciais que permitem o casamento entre pessoas do mesmo sexo, conferir: <http://www2.stf.jus.br/ portalStfInternacional/cms/destaquesNewsletter.php?sigla=newsletterPortalInternacionalDestaques\&idConteudo=238515> e <http://www.cnj.jus. br/images/imprensa/resolução_n_175.pdf>. Acesso em: 30/09/2015. Para informaçóes sobre o Estatuto da Família, conferir: <http://www.camara. gov.br/proposicoesWeb/prop_mostrarintegra;jsessionid=954A7F13B06F- 
4DFC9AF38AC0F01AEAE8.proposicoesWeb1 ?codteor $=1159761 \&$ filename=Tramitacao-PL+6583/2013>， <http://www2.camara.leg.br/ comunicacao/institucional/noticias-institucionais/enquete-sobre-estatuto-da-familia-chega-a-um-milhao-de-acessos $>$ e <http://g1.globo.com/politica/noticia/2015/09/comissao-aprova-definir-familia-como-uniao-entre-homem-e-mulher.html>. Acesso em: 30/09/2015.

5. A cidade conta também com outros coletivos LGBT, como setoriais de partidos políticos e coletivos universitários.

6. CAMPINAS. Decreto no 14.787, de 28 de junho de 2004. Reorganiza a Coordenadoria de Proteção Especial do Departamento de Cidadania da Secretaria Municipal de Assuntos Jurídicos e da Cidadania e dá outras providências. Diário Oficial do Município, 2004, p. 8. Disponível em: <http:// bibjuri.campinas.sp.gov.br/index/visualizaratualizada/id/84916>. Acesso em $11 / 12 / 2014$.

7. CAMPINAS. Lei no 9.809, de 21 de julho de 1998. Regulamenta a atuação da municipalidade, dentro de sua competência, nos termos do Inciso XVIII, do Artigo 5o, da Lei Orgânica do Município de Campinas, para coibir qualquer discriminação, seja por origem, raça, etnia, sexo, orientaçáo sexual, cor, idade, estado civil, condição econômica, filosofia ou convicção política, religião, deficiência física, imunológica, sensorial ou mental, cumprimento de pena, ou em razão de qualquer outra particularidade ou condição. Diário Oficial do Município, 22/07/1998, p. 3. Disponível em: $<$ http://bibjuri.campinas.sp.gov.br/index/visualizaratualizada/id/91864>. Acesso em: 18/12/2014.

8. CAMPINAS. Portaria no: 06 - 19 de novembro de 2004. Implanta o Protocolo Paidéia para Redução de Danos no Uso de Silicone Industrial e Hormonioterapia na População de Travestis e Transexuais no Município de Campinas. Diário Oficial do Município, 20/11/2004, p. 10. Disponível em: <http://bibjuri.campinas.sp.gov.br/index/visualizaratualizada/ $\mathrm{id} / 88053>$. Acesso em 18/12/2014.

9. CAMPINAS. Portaria no $\mathbf{7}$ 7.823/2012. Diário Oficial do Município, 28/09/2012, p. 65. Disponível em: <https://bibliotecajuridica.campinas. sp.gov.br/index/visualizaratualizada/id/90726>. Acesso em: 28/09/2015.

\section{Referências bibliográficas}

AVRITIZER, Leonardo. O Orçamento Participativo e a teoria democrática: um balanço crítico. In: ; NAVARRO, Z. (Org.). A inovação democrática no Brasil: o orçamento participativo. São Paulo: Cortez Editora, 2003.

CÂMARA, Cristina. Cidadania e orientação sexual: a trajetória do grupo triângulo rosa. Rio de Janeiro: Academia Avançada, 2002.

CARDOSO, Ruth. Movimentos sociais na América Latina. Revista Brasileira de 
Ciências Sociais, São Paulo, v. 1, n. 3, p. 27-37. 1987.

CARRARA, Sérgio. O Centro Latino-Americano em Sexualidade e Direitos Humanos e o "lugar" da homossexualidade. In: GROSSI, M. P. et al. (Org.). Movimentos sociais, educação e sexualidade. Rio de Janeiro: Garamond, 2005. Políticas e direitos sexuais no Brasil contemporâneo. Bagoas, n. 5, p. 147-231. 2010.

DANILIAUSKAS, Marcelo. Relações de gênero, diversidade sexual e politicas públicas na educação: uma análise do programa Brasil sem Homofobia. São Paulo, 2011. Dissertação (Mestrado) - Faculdade de Educação, Universidade de Sáo Paulo.

DOIMO, A. M. A vez e a voz do popular: movimentos sociais e participação política no Brasil pós-70. Rio de Janeiro: Relume-Dumará/ANPOCS, 1995.

FACCHINI, Regina. Falsa ameaça. Aliás. Estadão.com.br. 18/07/2015. Disponível em: <http://alias.estadao.com.br/noticias/geral,falsa-ameaca,1727566>. Acesso em: 25/09/2015.

. Conexões, processos políticos e movimentos sociais - uma reflexão teórico-metodológica a partir do movimento LGBT. Revista Advir, n. 28, p. 6-20. 2012.

Entre compassos e descompassos: um olhar para o "campo" e para a "arena" do movimento LGBT brasileiro. Revista Bagoas, Natal, n. 4, p. 131158. 2009.

. Sopa de letrinhas? - movimento homossexual e produção de identidades coletivas nos anos 1990. Rio de Janeiro: Garamond, 2005.

FALCÃO, Thiago Henrique de Oliveira. Queixas, denúncias e desfechos: um estudo sobre o acolhimento e encaminhamento de denúncias em serviços especializados em violência homofóbica. Campinas, 2012. Relatório Científico: Pagu - Núcleo de Estudos de Gênero, Unicamp.

FRY, Peter. Da hierarquia à igualdade: a construção histórica da homossexualidade no Brasil. In: Para inglês ver. Rio de Janeiro: Zahar, 1982.

GOHN, Maria da G. História dos movimentos e lutas sociais: a construção da cidadania dos brasileiros. São Paulo: Edições Loyola, 1995.

GREGORI, Maria Filomena. Viraçâo: experiências de meninos nas ruas. São Paulo: Companhia das Letras, 2000.

MACRAE, Edward. A construção da igualdade: identidade sexual e política no Brasil da "abertura". Campinas: Editora da Unicamp, 1990.

MARIANO, Ricardo. Religião e política nas eleições presidenciais de 2010. Trabalho apresentado ao GT 19 - Religião e modernidade no XV Congresso Brasileiro de Sociologia, Curitiba, Paraná, 2011.

PARKER, Richard. Civil Society, Political Mobilization, and the Impact of HIV Scale-up on Health Systems in Brazil. Journal of Acquired Immune Deficiency Syndromes and Human Retrovirology, v. 52, 2009. 
PECHENY, Mario.; DEHESA, Rafael. Sexualidades y políticas en América Latina: un esbozo para la discusión. In: SONIA, C.; PARKER, R. Sexualidade e política na América Latina: histórias, intersecções e paradoxos. Rio de Janeiro: ABIA, 2011. p. 31-79.

PORTAL RAC. Câmara de Campinas renova metade dos vereadores. 2012. Disponível em: <http://portal.rac.com.br/noticias/index_teste.php?tp=eleicoes-2012\&id=/148391\&ano=/2012\&mes=/10\&dia=/07\&titulo=/camara-de-campinas-renova-metade-dos-vereadores $>$. Acesso em: 10/05/2015.

RODRIGUES, Silvia A. "Fazer-se no Estado": uma etnografia sobre o processo de constituição dos "LGBT" como sujeitos de direito no Brasil contemporâneo. Campinas, 2014. Tese (Doutorado) - Instituto de Filosofia e Ciências Humanas, Universidade Estadual de Campinas.

RUBIN, Gayle. Thinking sex: notes for a radical theory of the politics of sexuality. In: VANCE, C. (Org.). Pleasure and Danger: exploring female sexuality. Londres: Routledge and Kegan Paul, 1984.

SAFATLE, Vladimir. Os novos reféns. Folha.com.br. 2012. Disponível em: <http://www1.folha.uol.com.br/fsp/opiniao/72187-os-novos-refens.shtml>. Acesso em: 10/05/2015.

WAMPLER, Brian. A difusão do Orçamento Participativo brasileiro: "boas práticas" devem ser promovidas? Opinião Pública, Campinas, v. 14, n. 1, jun. 2008. Disponível em: <http://dx.doi.org/10.1590/S0104-62762008000100003>. Acesso em: 10/05/2015.

ZALUAR, Alba. Pobres, indóceis e cativos. Folha.com.br. 2001. Disponível em: <http://www1.folha.uol.com.br/fsp/resenha/rs1301200103.htm>. Acesso em: 10/05/2015.

ZANOLI, Vinicius. FACCHINI, Regina. Conexôes, atores, políticas sexuais e cidade: uma reflexão a partir da trajetória do grupo Identidade de Campinas/SP. Ponto Urbe, v. 6. 2012. Disponível em: <http://pontourbe.revues. org/226>. Acesso em: 10/05/2015.

ZANOLI, Vinicius. Fronteiras da politica: relaçôes e disputas no campo do movimento LGBT em Campinas (1995-2013). Campinas, 2015. Dissertação (Mestrado) - Instituto de Filosofia e Ciências Humanas, Universidade Estadual de Campinas.

Processos políticos e a produção de papéis e significados: uma análise das relaçóes entre o Estado e o movimento LGBT na criação do Centro de Referência GLTTB de Campinas-SP. Primeiros Estudos, São Paulo, n. 4, p. 156-166. 2013. Disponível em: <http://dx.doi.org/10.11606/issn.22372423.v0i4p156-166>. Acesso em: 10/05/2015.

WEEKS, Jeffrey. Sexuality and its Discontents: meanings, myths \& modern sexualities. Londres: Routledge and Kegan Paul, 1985. 
autores Vinícius Pedro Correia Zanoli

É Doutorando em Ciências Sociais, na área de Estudos de Gênero, na Unicamp;

Thiago Henrique de Oliveira Falcáo

É Mestrando em Antropologia Social, PPGAS/Unicamp.

Recebido em: 17/05/2015

Aceito para publicaçáo em: 20/02/2016 